\title{
Empirical Research on Community Participation of Xiaoqing River Ecological Improvement Project in China
}

\author{
Yanlei Hu \\ Tianjin University, Tianjin, 300072, China \\ sss_huyl@ujn.edu.cn
}

Keywords: Community Participation; Ecological Improvement; Empirical Research.

\begin{abstract}
This paper uses empirical research methods, including case analysis and surveys, to analyze the Xiaoqing River Ecological Improvement Project in Jinan, China. We found that this project has cost more than 10 Billion RMB over nearly eight years. However, pollution remains a major issue. We argue that this is due to the top-down approach adopted by Jinan government, which has failed to provide a comprehensive approach to the ecological problems. As such, we suggest that only a bottom-up, participatory approach, led by local community leaders, can solve the ecological issues.
\end{abstract}

\section{Introduction}

Water pollution of rivers loom large in environmental pollution with the increasing development of manufacturing industry and the speed of urbanization in China. In recent years, public participation in community-based environmental activities attracted the attention of the governors, public policy analysts and experts. ${ }^{[1]}$ For instance, in developed countries, the public and communities usually collected environmental data with reference to environmental quality and wildlife monitoring in North America, ${ }^{[2]}$ whilst with reference to the monitoring of wildlife species distribution and populations in the UK and Australia. In addition, data from the public may be used to inform and reinforce environmental management in developing countries. Therefore, community and the public play a more and more important role in environmental governance and ecological improvement from the West to the East, especially in China. With the recognition of communities as important stakeholders in influencing environmental management and development interventions, community participation was significant emphasized. ${ }^{[3]}$ For instance, in some developed countries, self-directed rural communities usually take the lead or significant action in the ecological improvement of the environment or the natural resources on which they depend. While there are more and more researchers found that community play an important role in ecological improvement from the West to the East, community participation of water environmental improvement has rarely been systematically investigated in the existing literature in China.

Therefore, in this paper we present a case study of what kind of the role of the local government and the community along Xiaoqing River in the Ecological Improvement Project (EIP) of Xiaoqing River. By reviewing the long period (nearly eight years) of the project, we found that the most serious problem was the dominant role of local government in the EIP, and show the specific characteristics of this government-oriented model of Ecological Improvement. We also discuss how the distinctive nature of the community along the River could play an important role in improving water environment. Our research enriches the EI literature by adding the local community into the improving project. We believe our study has important implications for both local governments and communities facing water pollution problems.

\section{Case study: EIP of Xiaoqing River}

The problem of water pollution aggravated sharply with quickly developing of manufacture industry in China. For example, according to China National Environment Statistic Bulletin of each year, water pollution was a quite high proportion of environment pollution and disruption accidents during the period of the year of 2001 to the year of 2007, and was the first frequency of each kind of 
environmental pollution accidents. Xiaoqing River is one of the most important river in Jinan. In 1980s, there were established thousands of industry enterprises without sewage disposal facilities along its banks with increasing steps of industrialization. On the other hand, the numbers of the population lived two sides of the river increased extensively as well as the quantity of sanitary waste was multiplied up. The industry of aquiculture and lotus planting were devastated with extinction of aquatic life for its severe water pollution of Xiaoqing River. It has been a very dirty and smelly river in those days. In 2006, local governments established some formal authorities or agencies to treat and improve ecology of the Xiaoqing River comprehensively, such as Leading Group of Comprehensive Treatment Project of Xiaoqing River, Construction Headquarters of Xiaoqing Project. On 25 June 2007, the Investment and Financing Center of Construction and Development of Xiaoqing River was formally established. EIP of Xiaoqing River was treated nearly for eight years with more than 10 million RMB investments till now. However, there are still many serious ecological problems of Xiaoqing River revealed by the interviews of public officials, Department of Water Environmental Improvement (DWEI), and citizens lived along Xiaoqing River, and some news or internal reports of Xiaoqing River recently. i. The water quality of Xiaoqing River is still far away from the V class water quality. ii. Both ecological landscape and wetland did not developed for lacking of financial investment of ecological construction of Xiaoqing River. iii. There was seldom policy to support the recycling program of reclaimed water. Furthermore, there are some other ecological problems of Xiaoqing River including lack of public sanitation, a large quantity of ground rubbish, and pollution caused by environmental changing. On the whole, the EIP cost more than ten billions RMB. However, pollution remains a major issue.

Based on the secondary-sourced data, we came up with semi-structured interview questions and visited four officials of Jinan Environment Protection Bureau (JEPB), four public officials of a street office ${ }^{(1)}$ along the river, and ten residents who live along Xiaoqing River. For JEPB, we interviewed the manager, vice manager and two staff member of the DWEI. This department is directly in charge of protecting water resource and improving ecology of Xiaoqing River. For the street office, we interviewed two middle-level members on the management side and two staff members. And the interviews were conducted with a sufficient variety of knowledgeable informants in the DWEI and the street office along Xiaoqing River to provide multiple perspectives. We interviewed the citizens at random. In interviews, we asked the actual role and the ideal role of community in the EIP, the current problems of community participation and its reason, what kind of incentive methods of enhancing community participation, and the role of government in enhancing community participation. The interviews material provided a subjective account of developments to be compared with the initial "objective" data obtained from the secondary sources, such as news or report from internet or newspapers. Subsequently, some of the case histories were shared with and checked by the informants. During our primary data collection process, we interviewed the Chief Manager of JEPB. He introduced the DWEI, which is in charge of water and ecological improvement of Xiaoqing River. Some key issues about the fiscal investment, the current crucial water pollution problems and the current situation of community participation were interpreted and discussed.

Based on the qualitative data we identified the key problems and reasons of community participation in this project, and its countermeasures. More specifically, the key issues examined in the case were as follows. (1)What kind of the role can community play in the EIP of Xiaoqing River? (2)Do you think there is community participation in this EIP? If there is, could you tell us at least one illustration? (3)Do you think there is a problem of lacking community participation in this EIP? If there is, why? (4)What incentive measures of enhancing community participation should be established by the local government?

${ }^{11}$ In China, there was not community instead named as sub strict office. 


\section{Discussion}

\subsection{Dominated local government in ecological improvement}

Our interviews and literature study show that there are two main characteristics of the EIP of the Xiaoqing River. First, public officials especially from local government undertook both the role of steering and the role of paddling at the same time. On the contrary, other important stakeholders including private enterprises, community and citizen lived along the River seldom participate into the project initiatively but passively. Second, the financial investment was mainly from local public finance on the EIP of Xiaoqing River. And the number of the investment is more than ten billion RMB. However, the financial investments of enterprises or social organizations were too small to be counted. And most of social organizations usually are in small size and little funds. For example, the registered capital of Green Qilu is only ten thousands RMB, and it received donation with a very low quantity. In the first quarter of 2015, it totally received 1,283 RMB. ${ }^{[4]}$ However, the greater government involvement increases the risk of excluding of vital community participation. ${ }^{[5]}$ It is a serious problem faced with the EIP of Xiaoqing River. It suggest that stakeholders should take part in as early as possible from project concept development and planning to implementation and monitoring and evaluating outcomes in order to increase the quality and robustness of decisions. For instance, in Japan, local social organizations, NGO and simple residents are the dominated motivation in the process of local environmental improvement movement. Especially social organizations play a very important and effective role on local environmental improvement. Since 1990s, social organization undertook more and more public responsibility in the field of public service including environmental service and improving action. Therefore, the EIP of Xiaoqing River calls for a comprehensive cooperation of local governments, communities, social organizations and citizens.

\subsection{Lacking legal basis of River-leader system}

In any society, as laws are necessary that good manners may be preserved, so good manners are necessary that law may be maintained. It is well known that the government and other intermediary institutions play a role in bringing together all the stakeholders by creating the legal and institutional platforms for engagement, particularly in cases where communities and common property are involved and user rights are uncertain. ${ }^{[6]}$ Hence, any good system should be based on good laws. Both the government and citizens came to know the key point in China. In recent years, some environmental protection laws were established in China. But there is not a law of River-leader system till now. In the EIP of Xiaoqing River, River-leader Responsibility system is consisted of two level of River-leader including each chief executive of party committee and the street office. ${ }^{[7]}$ In practice, River-leader system faced some institutional dilemma, such as lacking of executive power and institutional guarantee, without legal basis. It resulted the conflicted relation among each stakeholder including the local government, enterprises, social organizations and citizens; and it also resulted a contradicted opinion between the government side and the society side. The government side noted that enterprises and citizens should account for the water pollution; on the contrary, the society side claimed that the key accounted subject is local government. On the whole, EIP of Xiaoqing River is not governed by law but by man in a River-leader system. Therefore, River-leader system should be legalized by supplemented with some detailed legal provisions.

\subsection{Institutional defection of ecological improvement system}

As a typical top-down executive system, it has institutional defection of lacking bottom-up institution or approaches to join the EIP of Xiaoqing River. In such a system, the local government just like a man encumbered with large parcels. Furthermore, environmental accountability system of each county also is a hierarchy system in which the executive officials were supervised by their superiors. We reviewed some typical cases of urban environmental improvement overseas, such as Reconstruction of Ruhr Industrial Base. In that project, most of experts, scientist, and local government noted that the central force is comprehensive cooperation and participation by those multiple stakeholders such as local enterprise, social organization, and residents. However, 
River-leader system could not provide the above community participation approaches for those multiple stakeholders. Obviously, it is a serious institutional defection of River-leader system. Luther Gulick, a famous social scientist in the field of organization management, argued that "in any practical situation the problem of organization must be approached from both top and down... In that case one would develop the plan of an organization or reorganization both from the top downward and from the bottom upward, and would reconcile the two at the center." ${ }^{[8]}$ Even though River-leader system worked very well till now, its institutional defections would be a dilemma in the future. For instance, it would be ineffective or inefficient once the officials of local government are lack of motivation. Therefore, it is necessary to improve the River-leader system by constructing community participation approach.

\subsection{Small quantity and size of Social Environmental Organization}

It was well known that nongovernmental organizations (NGOs) play an increasingly prominent role in ecological improvement, participating in many activities-negotiation, monitoring, and implementation - traditionally reserved to states. Some claim that the expansion of NGOs in these institutions "may signal an end or at least a fundamental challenge to the concept of state sovereignty and to the primacy of the state in international law and relations". However, the quantity of environmental NGO in Jinan is still at a very low level. For instance, one of the managers of Green Qilu was established the first environmental NGO named as Walk into the Nature both in Jinan and Shandong Province on $1^{\text {st }}$ June of 2002. But it was a hard way to run the NGO very well. On $29^{\text {th }}$ March of 2013, it was informed to be legally closed for non-conformance with regulation of annual inspection. At present, Green Qilu is the only one active and effective environmental NGO in Jinan. Therefore, the extent of community participation decreased or restricted by the small quantity and size of environmental NGO in Jinan. And it is also a common serious problem in China.

\section{Conclusion}

In this paper, we studied how the Chinese environmental protection government (especially local) conceived the innovation of a top-down system named as River-leader system. We also showed both advantages and disadvantages of this top-down system in water environmental improvement. We found that River-leader system, which was born from Chinese party system and political institution, played a much more dominate role than bottom-up system constituted with community, social organization and citizens in the case of EIP of Xiaoqing River. Our findings showed that the dominated position of local government, decreased participation motivation of public officials and citizens, low level of social environmental organization and other serious problems of community participation in EIP of Xiaoqing River. Hence, we suggest that River-leader system should be improved by supplementing of its legislation basis, incentive system and cooperation system with social environmental organization, such as outsourcing some public environmental service to those social environmental organizations, established a Public Private Partnership (PPP) model of multi financing system. However, the River-leader system is quite distinct from other developed countries but work well in China till now. So it maybe referenced both by some developing countries and developed countries with serious water pollution problems.

\section{Acknowledgement}

The author would like to acknowledge the funds of China Social Science Research of Education Department (NO. 11YJC810013), the funds of Soft Science of Shandong Science and Technology Committee (NO. 2015RKB01019), the funds of Humanity Social Science of Shandong Province (NO.15-ZX-TZ-03) . 


\section{References}

[1] Alana Boland, Jiangang Zhu. Public participation in China's green communities: Mobilizing memories and structuring incentives, Geoforum, 43 (2012), p147-157.

[2] Savan, B., Morgan, A. J., \& Gore, C. Volunteer environmental monitoring and the role of the universities: The case of Citizens’ Environment Watch, Environmental Management, 31 (2003), p561-568.

[3] Stringer, L.C., Paavola, J.. Participation in environmental conservation and protected area management in Romania: a review of three case studies, Environmental Conservation, 40(2013), p138-146.

[4] Green Qilu. http://www.greenqilu.org/Item/ Show.asp?m=1\&d=409, 2015.

[5] Maurice A. Rawlins, Leon Westby. Community participation in payment for ecosystem services design and implementation: An example from Trinidad, Ecosystem Services, 6(2013), p117-121.

[6] Kolinjivad, V. K., Sunderland, T.. A review of two payment schemes for watershed services from China and Vietnam: the interface of government control and PES theory, Ecology and Society, 17 (2012), p10.

[7] Jinan Environmental Protection Bureau. Lessons and Suggestions of Comprehensive Ecological Improvement in the Project of Xiaoqing River in Jinan, 2012.

[8] Luther Gulick, Lyndall Urwick, eds. Notes on the theory of Organization, Papers on the Science of Administration, New York: Institute of Public Administration, 1937, p3-13. 